\title{
The Impact of Culture and Gender on the Production of Online Speech Acts among Jordanian Facebook Users
}

https://doi.org/10.33806/ijaes2000.19.2.9

\author{
Ala'Eddin Abdullah Ahmed Banikalef \\ Jadara University, Jordan
}

\begin{abstract}
This study of speech acts offers deep insights into the social structure and gender differences of any speech community. Most relevant research on online speech acts has shed much light on Western speech communities, neglecting the speech act behavior of Arabic speaking communities. This study aimed to examine the influence of gender differences and the Jordanian cultural norms on the use of speech acts in Facebook Status Updates (FSUs). A total of 1718 FSUs were collected over a period of 2 months. Then, they were categorized according to Searle's speech acts taxonomy. Results showed that women made an average of 6 updates to their Facebook status, while men averaged four. In addition, the results revealed that females and males differ in their linguistic repertoires. Male participants were inclined to use more assertive speech acts, whereas females were more likely to use expressive speech acts. Islam and tribalism are factors that were found to play an important role in defining the cultural norms of the Jordanian speech community.
\end{abstract}

Keywords: Facebook status updates, gender differences, Jordanian speech community, netspeak language, Searle's taxonomy

\section{Introduction}

Communication is essential for human existence. Communication has been described differently by different scholars. Banikalef (2015) defines communication as a mutual process of sending and receiving facts, ideas, opinions, or emotions by two or more people. Okunn (2002) tries to widen the definition of communication to include any process which we need to understand others and any attempt to be understood by them. Thus, communication could be seen as a process of sharing and expressing thoughts, opinions, feelings, emotions, information, etc. It always tries to fulfill social and individual needs. Austin (1962) stated that communicative acts such as sharing information, raising questions, or expressing feelings are all falling within the scope of 'speech act', a long established area in pragmatics. In line with Austin, Searle (1975) suggests that speaking or writing a language is performing acts of speech such as making a statement, giving commands, asking questions, making promises, and so on. Generally speaking, the core assumption of Speech Act Theory (SAT) is that communication consists of performing actions.

Social network site (SNS) is considered a unique communication channel, including features that allow users to easily share their interests, values, and beliefs with others (Wilson, Gosling and Graham 2012). Among all social 
networking websites, Facebook is by far the most popular. As of March 2018, Facebook reached a number of 2.19 billion active monthly users worldwide (Statista.com, 2018). 73\% of them are young users and their ages ranged from 18 to 28 years old.

Facebook makes available an ample data to examine the communicative acts of individuals in a social network woven by interesting events, culture, topics, etc. Microblogging is one of Facebook's most popular features (Buechel and Berger 2012). This feature allows Facebook users to share text-based messages (e.g. status updates) about their thoughts, emotions, and activities with other Facebook users. These status updates can be a rich source of researchers interested in understanding the linguistic features of the online language.

Many researchers assert that Facebook status updates (FSU) reflect users' views and feelings, and allow them to share the activities about which they care with each other every time ( Banikalef, Marlyna and Ashinida 2014; Howlader, Pal, Cuzzocrea and Kumar 2018). These status updates comprise various types of speech acts that are generally shared in a more spontaneous and a less well organized manner (Ling, Baron, Lenhart and Campbell 2014). Similarly, Wilson, Gosling, and Graham (2012) assert that Facebook presents a notable opportunity for social scientists to observe a wide variety of human behavioral and social phenomena in a natural setting. Buffardi and Campbell (2008) also affirm that examining Facebook is theoretically similar to examining culture throughout time. Research shows that Facebook users represent their beliefs, values, and interests accurately in their online profiles. These beliefs and practices are, in fact, a reflection of people's offline culture.

However, as yet, very little research has applied Speech Act Theory to examine online communication in Facebook or social media. Such research was done in relation to different contexts such as the English and the European (Carr, Schrock and Dauterman 2012; Stidham2014; Asian(Ilyas and Khushi 2012; Maslida Yusof and Karim Harun 2015), or within African context (Nartey 2013; Stoll 2015). Even though these researches are abundant in their contexts, there is a scarcity of such research within the Jordanian context. Most of the speech acts research in the Jordanian context has focused on the same subjects relating to Interlingua or cross-cultural examination of a certain speech act. The available data is, therefore, incomplete and provides only one side of the picture of how young Jordanian males and females perform speech acts, whether in online or offline situations. Therefore, the current study attempts to bridge this gap in the literature and provide some understanding of how males and females differ in their discursive use of language in Facebook status updates.

According to Nartey (2013: 116), the few linguistic studies on SNSs have generally focused on English and European languages possibly because SNSs evolved from these regions. In this line, Banikalef and Bataineh (2017) stated that future research should consider the effects of gender differences on language use in the virtual world. Therefore, it would be helpful to understand how male and female Jordanian Facebook users are using speech acts in SNSs and, particularly, Facebook status updates. By applying speech act recognition on the Facebook 
status update, the researcher may outline a general framework for data analysis. This framework can be used both as an analytic lens for understanding the communication acts used by Arab Jordanians youth on social network sites e.g., Facebook, and as a mirror to reflect the Arab Jordanian social and cultural norms in the online community.

In short, Facebook status updates are mainly posted by both genders (male and female). Thus, any linguistic variation on the basis of gender will be taken into account in this study. The current study thus focuses on the use of contemporary virtual modes of communication, a domain that has not been much studied to date in relation to interaction among Jordanians. The aim of this study is to show that Jordanian Facebook users' ability to perform an act and decide its illocutionary reading is attained by creatively invoking and mobilizing features of the Jordanian cultural context.

\subsection{Objectives}

1. To identify the most frequent types of speech acts in the status updates posted by Jordanian males and female Facebook users.

2. To highlight the influence of culture and gender on the speech act production among the Jordanian males and females.

\section{Literature review}

The rapid growth of the internet and digital technology have improved individuals' communication in everyday life in which they use these online technologies to facilitate their social interactions (Al-Sa'diandHamdan 2005). Studies on Facebook assert that this digital domain offers many novel opportunities for studying social behavior that previously had to depend on behaviors that were hard to assess (e.g., making friends, chatting, updating status messages) (Baker, 2013). Therefore, it is valuable to consider Facebook as a dynamic database of social attitudes with new data being updated in real time.

Previous studies on Facebook have paid more attention to topics such as what people are doing on Facebook (Jamtvedt, Young, Kristoffersen, O'brien and Oxman 2006; Rothen et al. 2016), what is the role of Facebook in changing the political regimes in some Arab countries, and how speech acts are presented on Facebook.

As mentioned earlier, some studies have examined why people use Facebook or what motivates individuals to use Facebook. Researchers have found that the purposes of using Facebook were mostly related to social and daily activities (e.g. having fun, contacting friends, and following news on Facebook) rather than educational and school-related purposes (Batenburg and Bartels 2017; Tandoc, Ferrucci and Duffy 2015 ). Therefore, it can be supposed that Facebook is seldom used for educational purposes. Other studies have supported these findings, concluding that Facebook is used typically to keep in touch with people and to enhance social ties (Ainin, Naqshbandi, Moghavvemi and Jaafar 2015; Boyd and Ellison 2008; Cravens and Whiting 2016; Jung and Sundar 2016)). According to them, Facebook has become part of users' daily routine. 
Other researchers have examined the possible role of SNSs, Facebook in particular, in changing the political regimes in some Arab countries. In Egypt and Tunisia, for example, SNSs sped up the revolution by helping to organize the rebels or the protesters broadcast their messages worldwide and galvanize international support for their revolution (Habib 2013; Vargas 2012). Bayat (2017) states that Facebook became one of the main factors that paved the way for the Arab Spring. He adds that Arab uprising and its virtual activists have added additional weight into the fact that online social networks can play a dynamic role in projecting a revolution in a society where individuals lack access to unify and mobilize themselves. Other studies have supported these findings, concluding that Facebook was an essential instrument in mobilizing political outcomes in the Arab Spring. They also served as a virtual channel for individuals of the region to tell their stories of the revolution, which played an inspirational role in neighboring countries (Acemoglu, Hassan and Tahoun 2017; Al-Rawi 2014; Farhan and Varghese 2018).

In the domain of studying speech acts in certain SNSs, Facebook in particular, literature is very scarce. In a article about the communicative functions of status updates on Facebook, Ilyas and Khushi (2012) explored how identities were created and represented through language. For the purpose of research, 60 participants were recruited. Their status messages were collected for 5 days and then classified according to Searle's taxonomy of speech acts. Searle classified speech acts into five categories, namely, assertive acts, directive acts, commisive acts, expressive acts, and declarative acts. The findings revealed that status updates were mostly constructed with expressive speech acts (33.33\%), followed by Assertive (28.07\%), Directives (18.12\%), and Commisives (2.32\%). Two categories were added to the original taxonomy, namely, Quotations (15.21\%) and Poetic Verses $(2.9 \%)$. The authors concluded that people use language not only for expressing themselves, but also for identifying their identities.

Nartey (2013), likewise, investigated the status updates of students of the University of Cape Coast (UCC) on "UCC GOSSIPZ", an online group page created on Facebook by UCC students. He tried to find out the different categories of speech acts used by Ghanaian university students to update their status on Facebook as well as the pragmatic underpinnings of these status messages. The findings showed that five speech acts appeared in the data set, namely, directives, assertives, expressive, commissives and quotations. The content analysis showed that directives were the most frequent speech act (35\%), followed by assertives (23.3\%), expressives $(21.7 \%)$, quotations $(11.7 \%)$ and commissives $(8.3 \%)$. The results also revealed that many intended meanings conditioned the messages that were used by the students to update their status. These include requests, asking questions, giving advice, suggestions, and confessions.

In the Jordanian context, Banikael and Bataineh (2017) studied the types of speech acts in the Facebook status updates. The data were gathered from 200 students from Irbid National University and Jadara University. The findings revealed that no declaration and commissives speech acts made by participants. However, three new speech acts were added to Searle's taxonomy, namely, God's 
invocations, humor, and quotations. The researchers concluded, "It is recommended that future research should question gender differences in Facebook status updates" (2017: 278). Therefore, the current study will strive to understand how gender interacts with speech acts in the virtual community (Facebook) which has become one of the most popular mediums of communication among Arab youths, in general, and Jordanian youths, in particular.

\section{Method}

\subsection{Subject and setting}

The study involved 100 undergraduate students (50 females and 50 males) all of whom were between 19 to 24 years of age. They were recruited from three universities, namely, Irbid National University, Yarmouk University, and Jadara University. These universities are located in the north of Jordan. The participants are purposely selected from different disciplines in the three universities. In order to easily access participants' status updates on Facebook, they are added to the researcher's Facebook page.

\subsection{Instruments}

Content analysis was applied to analyze the types of speech acts in the students' Facebook statuses. Samples of naturally occurring Facebook status updates were encoded using Searle's speech acts taxonomy (1969: 16). This means that each collected status update is manually classified into one of these five categories:

1. Assertives: utterances reporting statements of fact verifiable as true or false (e.g. Water freezes at zero degrees centigrade).

2. Commissives: utterances committing one to doing something (e.g. I promise to call you later).

3. Directives: utterances intended to get someone to do something (e.g. Stop shouting)

4. Declarations: utterances bringing about a change in the state of affairs (e.g. I now pronounce you husband and wife)

5. Expressives: utterances expressing speaker attitudes (e.g. That's a beautiful dress; I'm sorry for being so late.

\subsection{Data collection}

Facebook status updates (FSUs) were collected during May 2018 and the whole process took about two months. These status updates were in Arabic, English and Netspeak language. FSUs were, then, examined by their similarities and then placed into categories according to the similarities identified. The categories were assigned with codes before sorting them out. Codes are the simplified tags or labels, assigned to hold meaning to the descriptive or inferential information gathered during the research.

In content analysis, the reliability relies on whether and to what extent agreement can be reached among coders, judges, observers, or measuring instruments (Krippendorff 2011).Therefore, in order to enhance the reliability of the research, the analysis was undertaken in two stages: 
The first stage of analysis was first conducted by the researcher himself. He personally monitors the linguistic expressions of speech acts across these status updates and assesses the acts of speech by creating regularity of co-occurrence between the kinds of expressions and Searle's speech acts classification.

In the second stage, two raters were asked independently to confirm that the status updates matched the data in light of Searle's speech acts taxonomy. The two raters are $\mathrm{Ph} . \mathrm{D}$. holders in contrastive linguistics. They are Jordanian native speakers of Arabic, and they have adequate experience in the analysis of speech acts coding scheme. The researcher provided the raters with the collected status updates and asked them to code each one according to one or more of the types of speech acts that form Searle's taxonomy.

\section{Results}

Analysis of interpersonal status updates (in that they are developed for other friends) in Facebook offers a unique look at how users' constructing updates for others take into account several potential addressees. In a world that is becoming increasingly more global, it is no surprise then that the common form of communication is facilitated through speech acts.

For the purposes of identifying and evaluating the current study, the detailed annotation guideline is created for four of Searle's speech act basic classes that frequently occur in Facebook status updates: Commissives, Directives, Expressives, and Assertives. The speech act of declaration was omitted from such analysis because it was not found in the data, and consequently it is excluded. Examples from the collected data are given to clarify how these speech act classes are constructed in the data set:

1.Expressives: An expressive speech act occurs in utterances when one expresses his or her psychological state to the hearer. Typical cases are when the speaker greets, complains, apologizes, or thanks to the audience. In other words, this act expresses feelings toward (though not essentially about) the receiver. Expressive speech acts are common in Facebook status updates (FSU) because Facebook users often greet audiences at the beginning of a post " مساكم خيررد (2) "وطييه با حبايب (Happy and Good evening to all of you, my loved ones!) or

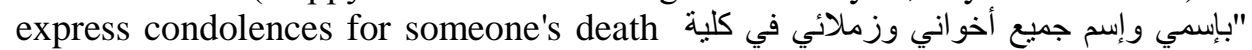
تكنولُوجيا المعلومات أتقدم بأحر التعازي الى أخي وزميلي وصديقي" (On behalf of myself, my brothers, and colleagues in the Faculty of Information Technology, I would like to express sincere condolences to our dear brother, colleague, and friend David Aliwansh). Expressive speech acts are found in a variety of other contexts such as a compliment, gratitude, congratulation, and an apology.

2.Representatives (Assertives): This act is used to get the receiver to form a belief and, as such, would be appropriate for identity construction and maintenance. It expresses the sender's belief in something that can be assessed as true or false. Representatives speech acts are found in a variety of other contexts such as suggesting, swearing, and concluding. This act is common in (FSU) because users always try to constitute their identity and maintain their personal self- 
image. In the status messages in Facebook domain, the researcher considered any utterance as a representative speech act when users explicitly confirmed or expressed their beliefs or hypotheses about the presence (or absence) of daily life events. Assertives are utterances of fact that get the receiver to form or " لا اله الا اله محدا رسول Attend to a belief. For example, if a Facebook user posts "لهاله(There is no God except Allah and Muhammad is the messenger of Allah), then this represents the Facebook user's own proposition/belief. This example is taken as Assertive "مخطى يا من تضن ان الله لا يستجيب أمنياتاك فاله يؤجل أمنياتتا و لا ينساها (You are mistaken if you think that Allah doesn't respond to your invocations; he may postpone them, but He never forgets them) or (Do not give up the invocation of Allah).

3.Commissives: This act occurs when the Facebook user commits to a future course of action such as promising, threatening, planning, and betting. The main purpose of this act is to confirm to the receiver that the Facebook user will perform some action in the future. For example, a Facebook user may write "صبايا رايحه اتسوق" بكره حدى حاب ييجي" (I am going shopping tomorrow, so anyone wants to go with me and take advantage of it). Decisions not to take an action are also considered as Commissive speech acts (e.g., "I am not going to the university tomorrow”" مو رايحة على الجامعة بكره _^^).

4.Directives: This act occurs when the writer asks the receiver to do something (e.g., a command). For example, the writer may make a request, ask a question, or issue an invitation or invocation. Many Directive utterances are posed as questions, so they are easy to recognize by the presence of a question mark. However, the language in CMC forums is informal and always ungrammatical, so many directives are written as a question but do not end in a question mark (e.g., "ليش ما حدى هون, وين الناس Where are you, people, why there is nobody here online."). Furthermore, many Directive speech acts are posed as a request for assistance from Allah. For example, a Facebook user may write, "O Allah, I ask you for good results in my exams يارب انجح في الامتحان واخذ علامات منيحة afl. Directives speech acts are found in a variety of contexts such as making a request, asking a question, giving advice, making an order, and invoking God.

In order to examine the effect of gender on the production of speech acts, the researcher starts by tabulating the content of the status updates used by the participants so as to explore possible variations in language patterns between male and female Facebook users. The tabulation of the data helped to clarify whether or not gender has an effect on how language is used and interpreted online since previous research had reported that males in synchronous CMC forums (e.g. chatting, IM) use more aggressive and abusive speech acts, while, female speech style was aligned and supportive (Altakhaineh, AL-Tkhayneh, and Rahrouh, 2019; Chaplin, 2015).

A total of 1718 status updates were collected and categorized according to their communicative functions. The first group (50 females) produced 1004 status 
updates. The second group (50 males) produced 714 status updates for two months. Results showed that women made an average of 6 updates to their Facebook status, while men averaged four. This means that women were more active on Facebook than their male counterparts.

Table. Speech act construction comparisons between male group and female

\begin{tabular}{|l|c|c|c|c|}
\hline Speech acts & \multicolumn{2}{|c|}{ Male } & \multicolumn{2}{c|}{ Female } \\
\hline & Frequency & Percentage & Frequency & Percentage \\
\hline Assertives & 297 & 41.6 & 220 & 21.91 \\
\hline Expressives & 195 & 27.3 & 412 & 41.04 \\
\hline Directives & 218 & 30.5 & 355 & 35.36 \\
\hline commissives & 4 & 0.6 & 17 & 1.69 \\
\hline
\end{tabular}

The above table details the results of the analysis. Taken together, the data suggest that Facebook status updates are constructed primarily with assertive among the male group by (41.6\%), followed by directives (30.5\%), expressives $(27.43 \%)$, but so rarely with commissives $(0.6 \%)$. On the other hand, a content analysis of speech acts found that expressive was the most common act among female participants $(41.04 \%)$, followed by directives (35.36\%), assertives (21.91\%), and rarely with commissives (1.69).

As it was stated earlier, one of the aims of this study is to find out the most frequent type of speech acts used by male and female Jordanian students in Facebook status updates (FSUs). Table reveals that the most common category used by males is assertives at (41.6\%). This means that males used FSUs as a source for facts and information (Banikalef and Bataineh 2017). They used FSUs mainly to discuss ideas such as the Syrian civil war, corruption issues in Jordan, and the Israeli-Palestinian conflict, rather than share personal information. When FSU highly constructed with assertive speech acts, it means that male participants are naturally more experienced in task accomplishment and addressing questions about facts. Thus, males viewed FSUs as a way to boost their influence and dominance in relationships. The high occurrence of this act, particularly in males' Facebook status updates, reflects their desires to be needed, appreciated, and admired by others. The following examples show how male participants used assertives speech acts in their Facebook status updates:

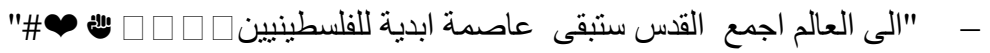

(To all the world, Jerusalem will remain the eternal capital of Palestine) (P: 62: M)

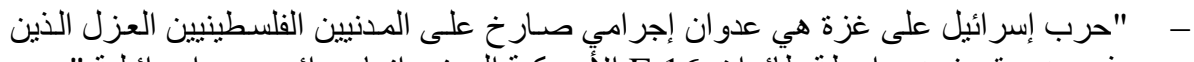

يذبحون ويقصفون بو اسطة طائر عات F-16 الأمريكية الصنع. إنها جر ائم حرب إسر الئر ائلية "

(Israel war on Gaza is a criminal outrageous aggression on defenseless Palestinian civilians who were slaughtered and bombed by US-made F-16 and missiles. It is Israel war crimes) (P: 55: M)

$$
\text { - - }
$$


(Google shares Jordanians their Independence Day celebrations) (P: 65: M)

$$
\text { - امة يسلب عر اقها ويمنها وشامها رامة لا يليق بها الحياة }
$$

(A nation that is dispossessed of its Iraq, its Yemen, and its Syria is not worthy of life) (P: 80: M)

On the contrary, figure 4.1 shows that the most frequent speech act among female participants is expressive (40.04\%). This may indicate that Jordanian women used FSUs mainly to enhance social connections and create relationships. Thus, they see the purpose of FSUs as a means to create and foster a close tie with the other party by talking about social issues, current events, and personal problems they are communally facing. By using expressive speech acts, the female participants tend to discuss their feelings and relationships in the FSU. They found it as a tool to create connections with others by sharing the ups and downs of their daily lives. In short, female participants constructed FSUs using expressive speech acts more than any other speech act. The examples below illustrate how female participants used expressive speech acts in updating their Facebook statuses.

$$
\text { - في بلادي : خاتمها الذي بيسار ها لا علاقه له بقلبها" - }
$$

(In my country, the girl's wedding ring in her left hand has nothing to do with her heart).

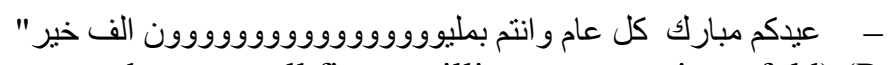

(Eid mubarek, every year and you are all fine a millioooooooon times fold) (P: 31: F)

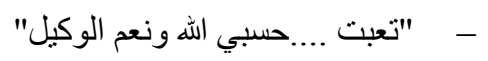

(I got tired of this life.... Allah [Alone] is sufficient for us, and He is the best disposer of affairs) (P: 36: F)

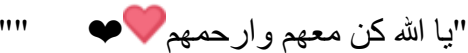
(May Allah be with our Syrian brothers and have mercy on them!) (P: 41: F)

As already stated, Searle's original speech act of declarations was excluded from this section because this act of speech never appeared in the data. This is because as Searle (1969) describes the illocutionary force of a declaration is to change the reality as a result of an utterance made. It is an act which brings into existence that which did not exist. Consequently, the participants did not produce utterances that could make changes in their realities. Moreover, Searle explains that declarations are normally made by individuals with official power (for example, ministers, lawyers, and juries). Clearly, undergraduate students - the sample of the current study - do not belong to such classes, given that there is only an equal relationship between the participants, which makes them communicate in spontaneous and friendly ways, and not to be worried about producing utterances that would change the world. The next section endeavors to answer the second research question. 
In short, the main aim of the current study was to find out the most frequent speech act used by male and female participants. In other words, it is a venture to unravel how males and females may differ in their linguistic behaviors in constructing FSUs. The findings show that the linguistic behaviors among male groups stem mostly from men's desire for power and control. Hence, the patriarchy of the Eastern man's mentality in which his behavior is motivated by the desire to dominate the subject matter and the opposite sex (Bener and Ghuloum 2011; Whiteoak, Crawford and Mapstone 2006). FSU, thus, was used by males as a space to express machismo. Overall, females used FSUs in order to enhance social connections and relationships, whereas males used them to boost social dominance.

In constructing FSUs, the main goal was for male participants to convey the meaning of their status updates to their friends, while female participants appeared to share their emotions and personal activities. It has been noticed that females often used FSUs to make connections and share items from their personal daily lives, while males use them as tools to gather information and enhance their social status. It has also been noted that females are generally the experts in "rapport talk." This type of talk represents skills of talking, expression, empathy, nurturing, and support (Abdel-fattah, 2010; Tannen, 1999). In contrast, males were experts in "report talk." This form of communication focuses on analyzing issues and solving problems (ibid).

To move deeper into the analysis, the researcher examined the influence of cultural norms of Jordanian society on the speech act behavior among the male and female participants. The cultural norms of a society are always displayed in the rules of speaking in a particular speech community (Bachrach, Kosinski, Graepel, Kohli and Stillwell 2012). The Jordanians are traditionally inclined to value collectivism, hierarchy, and interpersonal harmony (Banikalef and Marlyna 2013). Individuals in such a society are very aware of the hierarchical relationships among others. They should act according to their social roles in a particular situation and choose proper linguistic forms to specify the speaker's acknowledgment of the differences in social status and in other situations (ibid).

A content analysis of the Facebook status updates showed that the purpose of language use, for Jordanians, is for affirming or promoting relationships that have already been established, and thus they take particular care to maintain existing relationships. The findings also revealed that the cultural norms of the Jordanian speech community are strongly associated with two factors:

\section{Islam}

The main cultural norm that controls language use in the Jordanian speech community is the respondents' religious orientations. The general findings evidently indicate that the cultural norms and religious background, profoundly rooted in all participants, can strongly affect their linguistic choices in their native language. It has been widely recognized that the Arabic-Islamic social culture plays a significant role in the phraseology of constructing FSUs. 
A considerable number of religious expressions in the form of invocations were found to be used greatly by the participants. It is found that around 378 status updates contain the names of Allah. Invoking Allah's (God's) name in Jordanian Arabic is a common conversation feature in most types of speech acts and in directive speech act in particular. Moreover, the results displayed that the speakers preferred to use the expressive speech act in a combination of a directive speech act, and it always appears in the form of making supplications. Therefore, the occurrence of directive speech acts was more frequent than other relevant studies such as Carr, Schrock, and Dauterman (2012). This inconsistency in findings is related to the cultural and religious differences between Arabs and Western people that influence the linguistic realizations of speech acts. According to Banikalef and Marlyna (2013), the act of supplication does not frequently appear in a Christian speech community as compared to a Muslim speech community.

Consequently, it has been found that participants involve God's name in common speech practices such as greetings (e.g., may the mercy, peace and blessings of Allah be upon you), gratitude (e.g., may Allah reward you with good), appreciation (e.g., as God has willed), condolences (e.g., may Allah (God) bless his/her soul in Jennah). Such speech practices abound among Jordanians as a direct result of the conspicuous impact of Islam on the speech of Muslims, in general, and on the speech of Jordanians, in particular. This means that Islam is more than a mere belief to embrace; it is a way of life and an essential part of the Jordanian cultural heritage. As such, it remains an important part of their selfidentity. Other studies have supported these findings, concluding that the outward function of the Quran embraces all walks of life and covers the principles of the entire field of human affairs from the most personal matters (e.g., marriage, inheritance, love, etc.) to the most complex international relations (e.g., peace, war, economy, etc.) (Al Omoush, Yaseen and Alma'Aitah 2012).

\section{Tribalism}

In addition to Islam, Jordanian culture is based on tribalism with a robust sense of Arab identity rooted in its cultural system, particularly in the areas from which the data for this study were collected. Tribalism as a main part of modern Jordanian society still has an important authority over how Jordanians live, eat, celebrate, dress, solve conflicts, and make decisions.

The content analysis of the speech act in this study showed that the social life in Jordan has always focused on the family and attitude of the member toward the family. The majority of the participants used to identify themselves with their tribe's name (e.g. Bataineh, Shoubaki, Aslserhan), as the role and power of the family/tribe in supporting a member morally. Consequently, it can be said that the traditional tribe loyalty remains a powerful force in the Jordanian speech community. Moreover, the data showed that the ways of expressing different types of speech acts (e.g. invitations, greetings, and condolences) were greatly associated with the tribal speech system. This gave the new members of 
community reasons to acquire particular pragmatic and cultural norms to cope with the tribal linguistic system.

Like individuals in other cultures, the findings showed that Jordanians have special linguistic behaviors that are used in different social and religious occasions, such as wedding and funeral receptions. The Islamic holiday is Friday, and the Islamic festivals are Eid al-Fitr and Eid al-Adha. Participants used particular expressions to congratulate others on those occasions. On every Friday, for example, participants update their status messages sharing Dua'a (invocations) or greeting others, wishing them happiness and a blessed Friday.

It has been noticed also that tribalism plays a major main role in creating a male dominant society. Jordanian society is a male-dominated culture that favors or privileges men even in regard to language use. Therefore, Jordanians expect better language behavior from women than from men. Women are considered subordinate in the Jordanian society so that they should choose their expressions prudently. Consequently, they find Facebook status updates as an open medium that allows them to freely share their ideas, thoughts, and personal stories without having to think about the tribal rules of the Jordanian speech community.

In a male patriarchal society like the population of the current study, findings showed that Jordanian females rarely accept friend requests from male strangers. They also incline to share their posts mostly with other known female buddies. As a result, by using such Facebook privacy settings, they break male dominance. In short, women, in the Arab tribal culture in general and in Jordan in particular, are seen as the carriers of families' honor and reputation, as one of the female participants said. Since misbehavior by women can do more impairment to the family reputation than misbehavior by men. Therefore, maintenance of family honor is one of the uppermost values in Jordanian society. The findings indicate that Facebook users' gender has an impact on the speakers' language practices, market values, and ideologies.

\section{Conclusion}

The results of the analysis and a delineation of using each speech act were presented, and then the speech acts of the group of female users were compared to the speech acts of the group of male users. Searle's original speech acts definition and taxonomy were taken as the basis for the current study. The results revealed that the most common speech act used by the male participants was assertive whereas the most frequent speech act among the female participants was expressive. Overall, females used FSUs in order to enhance social connections and relationships while males used them to boost social dominance.

The findings of this study are consistent with the dominance theory that attributes differences between males and females to inequality of power between them. According to this view, women in male-dominated societies are obliged to exhibit qualities of weakness and are subordinate to men. Consequently, women's language is distinguished from men's language in a number of ways, including the use of empty adjectives, direct quotation, a special lexicon (e.g. color, fashion, 
and hair), and the use of a less sense of humor (Lakoff, 2003; West and Zimmerman 1987).

The findings also revealed that the cultural norms of the Jordanian speech community were strongly associated with two factors-Islam and tribalism. These linguistic motives invoke or yield the iconic identities of Jordanians speakers. Moreover, social and religious events such as wedding festivals, birthday celebrations, the month of Ramadan, the Arab spring, etc. played an important role in shaping the users' linguistic realization. That is to say, the different forms of speech acts derive their sociocultural importance not only from their religious background but also from other social, cultural, and political factors. These two factors are made to be the iconic identities of the speakers. The findings likewise correspond to Liao's (2010) claim that iconization relates to the linguistic behaviors that present the social group's inherent nature or essence.

Future studies are required to shed more light on the impact of virtual communities such as Facebook on users' linguistic attitudes. In the current study, only one type of social networking site was examined. Future research should also investigate other social networking sites usage purposes of the undergraduate participants. This study concentrated particularly on a limited number of populations. Future research on usage purposes of Facebook could be broadened to involve a wider demographic base, both internationally and geographically, to further find out to what extent the findings are generalizable.

\author{
Ala'Eddin Abdullah Ahmed Banikalef \\ Department of English \\ Jadara University \\ Jordan \\ alaeddin@jadara.edu.jo
}




\section{References}

Abdel-Fattah, Mahmoud. (2010). 'Arabic-Hebrew language-switching and cultural identity'. International Journal of Arabic-English Studies, 12: 183196.

Acemoglu, Daron, Tarek Hassan, and Ahmed Tahoun. (2017). 'The power of the street: Evidence from Egypt's Arab spring'. The Review of Financial Studies, 31 (1): 1-42.

Ainin, Sulaiman, Muzamil Naqshbandi, Sedigheh Moghavvemi, and Noor Jaafar. (2015). 'Facebook usage, socialization and academic performance'. Computers and Education, 83: 64-73.

Al-Rawi, Ahmed. (2014). 'The Arab spring and online protests in Iraq'. International Journal of Communication, 8 (1): 916-942.

Al-Sa'di, Rami and Jihad Hamdan. (2005). 'Synchronous online chat English : Computer-mediated communication. World Englishes, 24 (4): 409-424.

Al Omoush, Khaled, Saad Yaseen and Mohammad Alma. (2012). 'The impact of Arab cultural values on online social networking: The case of Facebook'. Computers in Human Behavior, 28 (6): 2387-2399.

Altakhaineh, Abdel Rahman, Khawlah Al-Tkhayneh and Hanan Rahrouh. (2019). 'The effect of the gender and culture of the IELTS examiner on the examinees' performance on the IELTS speaking test in the UAE context. International Journal of Arabic-English Studies, 19 (1): 33-52.

Austin, John. (1962). How to do Things with Words. The William James Lectures Delivered at Harvard University in 1955. Oxford: Clarendon Press.

Bachrach, Bachrach, Michal Kosinski, Thore Graepel, Pushmeet Kohli and David Stillwell. (2012). 'Personality and patterns of Facebook usage'. Proceedings of the 3rd Annual ACM Web Science Conference on - WebSci 12: 24-32.

Baker, Sally. (2013). 'Conceptualising the use of Facebook in ethnographic research: As tool, as data and as context'. Ethnography and Education, 8 (2):131-145.

Banikaelf, Ala'Eddin, and Khaleel Bataineh. (2017). 'A sociolinguistic study of speech act realization patterns in Jordanians' Facebook status updates'. International Journal of Linguistics, 9 (3): 264-283. https://doi.org/10.5296/ijl.v9i3.11245 (Retrieved on 1 August, 2018)

Banikalef, Ala'Eddin. (2015). Speech act analysis of Facebook status updates among young Arab Jordanians. Unpublished Ph.D Thesis, Universiti Kebangsaan Malaysia, Malaysia.

Banikalef, Ala'Eddin, Marlyna Maros and Ashinida Aladdin. (2014). 'Linguistic analysis of humor in Jordanian Arabic among young Jordanians Facebookers'. AWEJ, (3): 304-318.

Batenburg, Anika and Jos Bartels. (2017). 'Keeping up online appearances: How self-disclosure on Facebook affects perceived respect and likability in 
the professional context'. Computers in Human Behavior, 74 (15): 265276.

Bayat, Asef. (2017). Revolution without Revolutionaries: Making Sense of the Arab Spring. California: Stanford University Press.

Bener, Abdulbari and Suhaila Ghuloum. (2011). 'Gender differences in the knowledge, attitude and practice towards mental health illness in a rapidly developing Arab society'. International Journal of Social Psychiatry, 57 (5): 480-486.

Boyd, Danah and Nicole Ellison. (2008). 'Social network sites: Definition, history, and scholarship'. Journal of Computer-Mediated Communication, 13 (1): 210-230.

Buechel, Buechel, and Jonah Berger. (2012). 'Facebook therapy? Why people share self-relevant content online'. https://doi.org/10.2139/ssrn.2013148 (Retrieved on 16 June, 2018)

Carr, Caleb, David Schrock and Patricia Dauterman. (2012). 'Speech acts within Facebook status messages'. Journal of Language and Social Psychology, 31 (2): 176-196.

Chaplin, Tara. (2015). 'Gender and emotion expression: A developmental contextual perspective'. Emotion Review, 7 (1):14-21.

Cravens, Jaclyn and Jason Whiting. (2016). 'Fooling around on Facebook: The perceptions of infidelity behavior on social networking sites'. Journal of Couple and Relationship Therapy, 15 (3): 213-231.

Farhan, Naef and P. A Varghese. (2018). 'Facebook utilization and Arab spring movement: A study among Yemeni youth'. International Journal of Social Sciences and Management, 5 (1): 5-9.

Habib, Yousra. (2013). The uses and gratifications of Twitter in Egypt after Jan 25 revolution. Unpublished MA Thesis, The American University in Cairo, Egypt.

Howlader, Howlader, Kuntal Kumar Pal, Alfredo Cuzzocrea and Madhu Kumar. (2018). 'Predicting Facebook-users' personality based on status and linguistic features via flexible regression analysis techniques'. Proceedings of the 33rd Annual ACM Symposium on Applied Computing, 18: 339-345. https://dl.acm.org/citation.cfm?doid=3167132.3167166 (Retrieved on 29 June, 2018)

Ilyas, Sanaa and Qamar Khushi. (2012). Facebook status updates: A speech act analysis'. Academic Research International, 3 (2): 500-507.

Jamtvedt, G., Young JM, Kristoffersen DT, O'Brien MA and Oxman AD. (2006). 'Does telling people what they have been doing change what they do? A systematic review of the effects of audit and feedback'. BMJ Quality \& Safety, 15 (6): 433-436.

Jung, Eun and Shyam Sundar. (2016). 'Senior citizens on Facebook: How do they interact and why?' Computers in Human Behavior, 61 (8): 27-35.

Krippendorff, Klaus. (2011). 'Agreement and information in the reliability of coding'. Communication Methods and Measures, 5 (2): 93-112. 
Lakoff, Robin. (2003). 'Language, gender, and politics: Putting "women" and "power" in the same sentence. In Janet Holmes and Miriam Meyerhoff (eds.), The Handbook of Language and Gender, (160-178). New Jersey: Wiley-Blackwell.

Liao, Sze-wei. (2010). Identity, Ideology, and Language Variation: A Sociolinguistic Study of Mandarin in Central Taiwan. University of California: Davis, USA.

Ling, Rich, Naomi Baron, Amanda Lenhart and Scott Campbell. (2014). 'Girls text really weird: Gender, texting and identity among teens'. Journal of Children and Media, 8 (4): 423-439.

Maslida, Yusof and Karim Harun. (2015). 'Analisis Lakuan Tutur Dalam Ruangan Status Facebook'. Jurnal Komunikasi Malaysian Journal of Communication Jilid, 31 (2):151-168.

Nartey, Mark. (2013). 'A speech act analysis of status updates on Facebook: The case of Ghanaian University students'. Language in India, 13 (12):114-141.

Rothen, Stephane, Jory Deleuze, Laurent Karila, Sophia Achab, Gabriel Thorens and Yasser Khazaal. (2016). 'OR-91: What are people actually doing on Facebook?' Journal of Behavioral Addictions, 5 (S1): 38-39.

Searle, John. (1975). Indirect Speech Acts. Syntax and Semantics (Vol. 3). New York: Academic Press.

Statista.com. (2018). Number of monthly active Facebook users worldwide as of 1st quarter 2018 (in millions).

https://www.statista.com/statistics/264810/number-of-monthly-activefacebook-users-worldwide/ (Retrieved on 1 September, 2018).

Stoll, Brett. (2015). 'The effects of humorous Facebook posts on messenger credibility and social attractiveness'. The Hilltop Review, 7 (2): 3-18.

Tandoc, Edson, Patrick Ferruccib and Margaret Duffy. (2015). 'Facebook use, envy, and depression among college students: Is Facebooking depressing?' Computers in Human Behavior, 43 (10): 139-146.

Tannen, Deborah. (1999). 'Women and men in conversation'. In Rebecca Wheeler (ed.), The Workings of Language: From Prescriptions to Perspectives, 211-225. Westport: Praeger Publishers.

Vargas, Jose. (2012). Spring awakening: How an Egyptian revolution began on Facebook. The New York Times, 17. https://www.nytimes.com/2012/02/19/books/review/how-an-egyptianrevolution-began-on-facebook.html (Retrieved on 20 June, 2018)

West, Candace and Don Zimmerman. (1987). 'Doing gender'. Gender and Society, 1 (2): 125-151.

Whiteoak, John, Norman Crawford and Richard Mapstone. (2006). 'Impact of gender and generational differences in work values and attitudes in an Arab culture'. Thunderbird International Business Review, 48 (1): 77-91.

Wilson, Robert, Samuel Gosling and Lindsay Graham. (2012). 'A review of Facebook research in the social sciences'. Perspectives on Psychological Science, 7 (3): 203-220. 